\title{
Evaluation and Data Analysis of sol-gel method with acids to determine most effective sol-gel method
}

\author{
Aniska Ramsay and Joshua T. Moore*
}

\begin{abstract}
Synthesizing nanocomposite materials using sol-gel methodology is a cheap and effective method for creating quality $\mathrm{U}_{3} \mathrm{O}_{8}$ particles. To some degree acids can influence the synthesis of the nanoparticles by catalyzing the reaction. This paper presents important details comparing different acids used as catalysts in nanocomposite synthesis versus time manipulation to determine if an acid catalyst is necessary for the synthesis of $\mathrm{U}_{3} \mathrm{O}_{8} / \mathrm{SiO}_{2}$ nanocomposites.
\end{abstract}

\section{INTRODUCTION}

Nanoparticles are small particles with critical dimensions ranging from 1 to $100 \mathrm{~nm}$. Additionally, these particles are composed of interfacial layers. Materials constructed as nanostructures provide novel performance and new properties. Hence, with each new property constructed, each material will contain unique characteristics and critical length associated with the desired material. ${ }^{1}$ Solid nanoparticles form crystal structures through a specific arrangement of atoms. They have a long-range order which stems from the regularity of crystal arrangement extending through the crystal. ${ }^{1}$

The periodic table contains numerous elements leaving scientists with the daunting task to construct nanoparticles each day. This experiment will solely focus on the nano construction of the rare earth metal, uranium.

Uranium is number 92 on the periodic table. It is considered a rare earth metal, located in the actinide series. Due to this element containing natural characteristics in earth one can infer uranium can provide positive benefits for the earth due to its structure and ability to donate ions. Currently, uranium compounds are being studied more closely due to their potentiality in benefiting environmental safety in maximizing the utilization of limited sources. ${ }^{2-4}$

Upon studying uranium, the uranium framework contains linear structure ions and donor ions, through this characteristic one can confirm the donor atoms from the organic ligands will display uranyl equatorial positions which give rise to clusters, $1 \mathrm{D}$ chains, or 20 layers. ${ }^{5-10}$ The challenge with this element stems from the element displaying different physical and chemical properties existing in four different oxidation states of $+3,+4,+5,+6$. The oxidation states of +3 and +5 are very stable, leading this earth metal to exist in oxidation phase $\mathrm{UO}_{2}, \mathrm{U}_{3} \mathrm{O}_{8}$, and $\mathrm{U}_{3} \mathrm{O}_{11}$.

This study aims to discuss the proper methodology for synthesizing $\mathrm{U}_{3} \mathrm{O}_{8}$ using the silica gel matrix for enhanced catalysis reactions in an aqueous environment at atmospheric pressure, provide the proper techniques on creating simple cost-effective composites, with the addition of acetic acid $\left(\mathrm{CH}_{3} \mathrm{COOH}\right)$, Hydrochloric acid $(\mathrm{HCl})$ and standard no acid to create a homogenous mixture after heat treatment was conducted on uranyl acetate for final confirmation; the protocol with the two acids can aid in providing homogenous mixture similar to no acid catalysis. 


\section{MATERIALS AND METHODS}

\section{Sol-gel synthesis}

The regents used in the following experiments were methanol purchased from Fisher scientific, tetramethyl orthosilicate (TMOS), uranyl acetate, oxalic acid, sodium hydroxide, hydrochloric acid, phenolphthalein, and de-ionized nano pure water (DI water) filtered in-house using a Millipore system. All glassware used in these experiments were thoroughly washed and oven dried unless noted.

\section{Synthesis of $\mathrm{U}_{3} \mathrm{O}_{8} / \mathrm{SiO}_{2}$ Nanocomposites}

The synthesis of $U_{3} \mathrm{O}_{8} / \mathrm{SiO}_{2}$ nano composites was achieved with a solution containing 10 $\mathrm{mL}$ of TEOS, $0.6389 \mathrm{~g}$ uranyl acetate $\left(\mathrm{UO}_{2}\left(\mathrm{CH}_{3} \mathrm{COO}_{2}\right)_{2} \cdot 2 \mathrm{H}_{2} \mathrm{O}\right)$ and $3.5 \mathrm{~mL}$ of DI water. After, 2methyoxyethanol $\mathrm{C}_{3} \mathrm{H}_{8} \mathrm{O}_{2}$ was added to the solution and stirred for 20 minutes. The resulting preparation was aged for $72 \mathrm{~h}$. The sample was then dried at $100^{\circ} \mathrm{C}$ for $4 \mathrm{~h}$. In this work a material weight of $1.0556 \mathrm{~g}$ of material was calcinated under an $\mathrm{N}_{2}$ atmosphere for $4 \mathrm{~h}$.

\section{Synthesis of $\mathrm{U}_{3} \mathrm{O}_{8} / \mathrm{SiO}_{2}$ Nanocomposites with acetic acid $\mathrm{CH}_{3} \mathrm{COOH}$}

The synthesis of $\mathrm{U}_{3} \mathrm{O}_{8} / \mathrm{SiO}_{2}$ nanocomposites with $\mathrm{CH}_{3} \mathrm{COOH}$ was achieved with a solution containing $0.6389 \mathrm{~g}$ uranyl acetate $\left(\mathrm{UO}_{2}\left(\mathrm{CH}_{3} \mathrm{COO}_{2}\right)_{2} \cdot 2 \mathrm{H}_{2} \mathrm{O}\right), 3.5 \mathrm{~mL}$ of DI water, 2methyoxyethanol $\mathrm{C}_{3} \mathrm{H}_{8} \mathrm{O}_{2}$ and $1.0 \mathrm{~mL}$ of catalysis added to the solution and stirred for 20 minutes. The resulting preparation was aged for $72 \mathrm{~h}$. After it, the sample was dried at $100^{\circ} \mathrm{C}$ for 4 hours. In this work a material weight of $1.0556 \mathrm{~g}$ of material was calcinated for $4 \mathrm{~h}$ under an $\mathrm{N}_{2}$ atmosphere for $4 \mathrm{~h}$. Samples grown under basic catalysis with different time intervals values are: $1 \mathrm{~h}, 2 \mathrm{~h}$ and $4 \mathrm{~h}$.

\section{Synthesis of $\mathrm{U}_{3} \mathrm{O}_{8} / \mathrm{SiO}_{2}$ Nanocomposites with Hydrochloric acid (HCL)}

The synthesis of $\mathrm{U}_{3} \mathrm{O}_{8} / \mathrm{SiO}_{2}$ nanocomposites with $\mathrm{HCl}$ was achieved with a solution containing $0.6389 \mathrm{~g}$ uranyl acetate $\left(\mathrm{UO}_{2}\left(\mathrm{CH}_{3} \mathrm{COO}_{2}\right)_{2} \cdot 2 \mathrm{H}_{2} \mathrm{O}\right), 3.5 \mathrm{~mL}$ of DI water, 2methyoxyethanol $\mathrm{C}_{3} \mathrm{H}_{8} \mathrm{O}_{2}$, and $1.0 \mathrm{~mL}$ of catalysis added to the solution and stirred for 20 minutes. The resulting preparation was aged for $72 \mathrm{~h}$. After it, the sample was dried at $100^{\circ} \mathrm{C}$ for $4 \mathrm{~h}$. In this work a material weight of $1.0556 \mathrm{~g}$ of material was calcinated for $4 \mathrm{~h}$ under an $\mathrm{N}_{2}$ atmosphere for 4h. Samples grown under basic catalysis with different time intervals values are: $1 \mathrm{~h}, 2 \mathrm{~h}$, and $4 \mathrm{~h}$.

\section{Synthesis of Pure $\mathrm{U}_{3} \mathrm{O}_{8}\left(\mathrm{C}_{4} \mathrm{H}_{6} \mathrm{O}_{6} \mathrm{U}\right)$}

The synthesis of pure $\mathrm{U}_{3} \mathrm{O}_{8}$ was achieved with $1.0930 \mathrm{~g}$ of pure $\left(\mathrm{UO}_{2}\left(\mathrm{CH}_{3} \mathrm{COO}_{2}\right)_{2} \cdot 2 \mathrm{H}_{2} \mathrm{O}\right)$ calcinated for $4 \mathrm{~h}$ under an $\mathrm{N}_{2}$ atmosphere for $4 \mathrm{~h}$. Samples prepared in this manner serve as the control.

\section{RESULTS and DISSCUSION}

\section{Characterization of sol-gel samples}

FTIR measurements are presented in the figures below. conclusions are obtained with Fourier Transform infrared (FITR) instrumentation. This spectrum produces a profile of the sample thus creating a distinctive fingerprint which is then used to scan various known and unknown samples. FTIR is essential for detecting functional groups and characterizing covalent bonding information. There are many references of IR frequencies for various functional groups. This 
characterization is beneficial to the research because it allows for visualization and identification of any impurities in samples, and for indicating the absence or presence of nanocomposite production without impurities.

In the sol-gel process, the conversion of monomers to colloidal solutions creates an integrated polymer network. By adding strong acids to the sol-gel technique this creates a strong interconnected network. The goal of the experiment was to compare the two acids and prove if interconnection improved within the sol-gel samples. In the image below, the control was pure uranium salt. The Pure uranium salt confirms the solvent used was not contaminated and picked up both Silica and $\mathrm{OH}$ bonds which are standard.

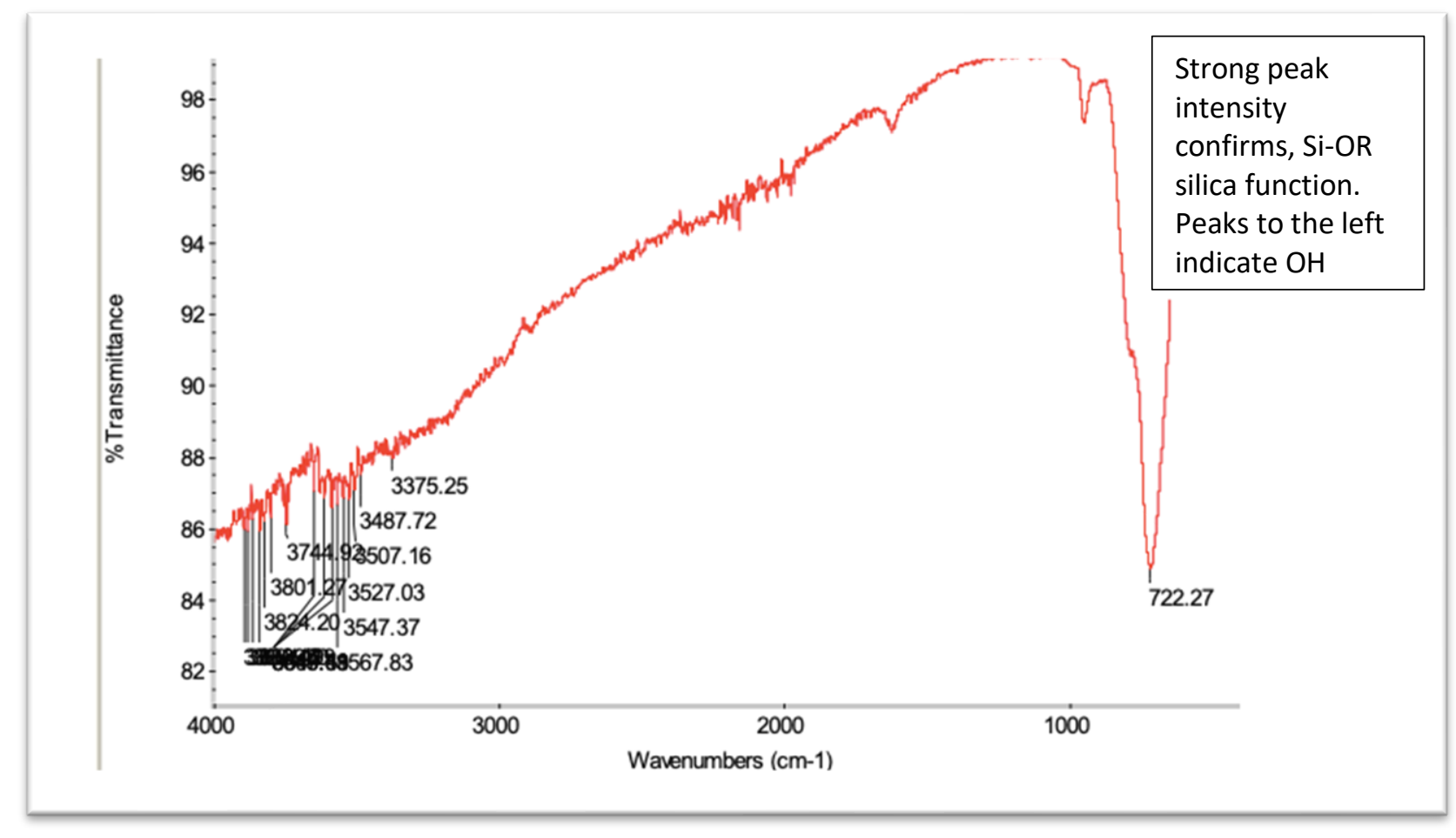

FIGURE1. Background spectrum shows pure uranium acetate, $\mathrm{C}_{4} \mathrm{H}_{6} \mathrm{O}_{6} \mathrm{U}$, confirming pure sample, and acts as control of the experiment. 
Once $\mathrm{U}_{3} \mathrm{O}_{8} / \mathrm{SiO}_{2}$ was constructed using no acids as catalysis, Figures 2 and 3 confirm the sol-gel method created the strong $\mathrm{OH}$ bonds around the $3000 \mathrm{~cm}^{-1}$ area on the graph confirming proper nano synthesis. Additionally, the yellow to dark olive color observed served as an additional indicator.

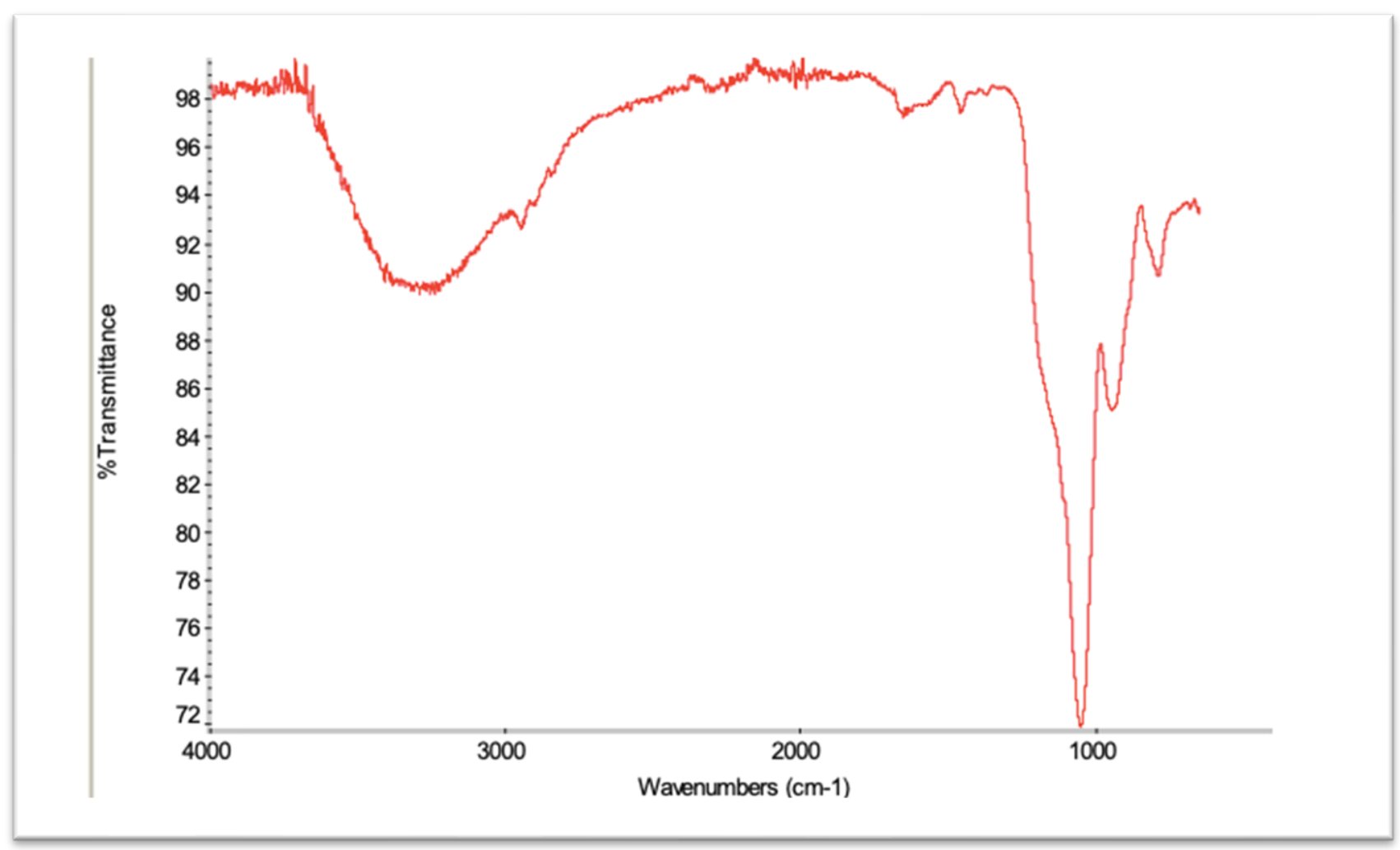

FIGURE 2. Background spectrum shows synthesis of $\mathrm{U}_{3} \mathrm{O}_{8} / \mathrm{SiO}_{2}$ nanocomposites, without the presence of catalysis. The wave located around $3254.55 \mathrm{~cm}^{-1}$ fingerprints $\mathrm{O}-\mathrm{H}$ bonds. The sharp peak around $1054.28 \mathrm{~cm}^{-1}$ indicates Si-OR stretch. 


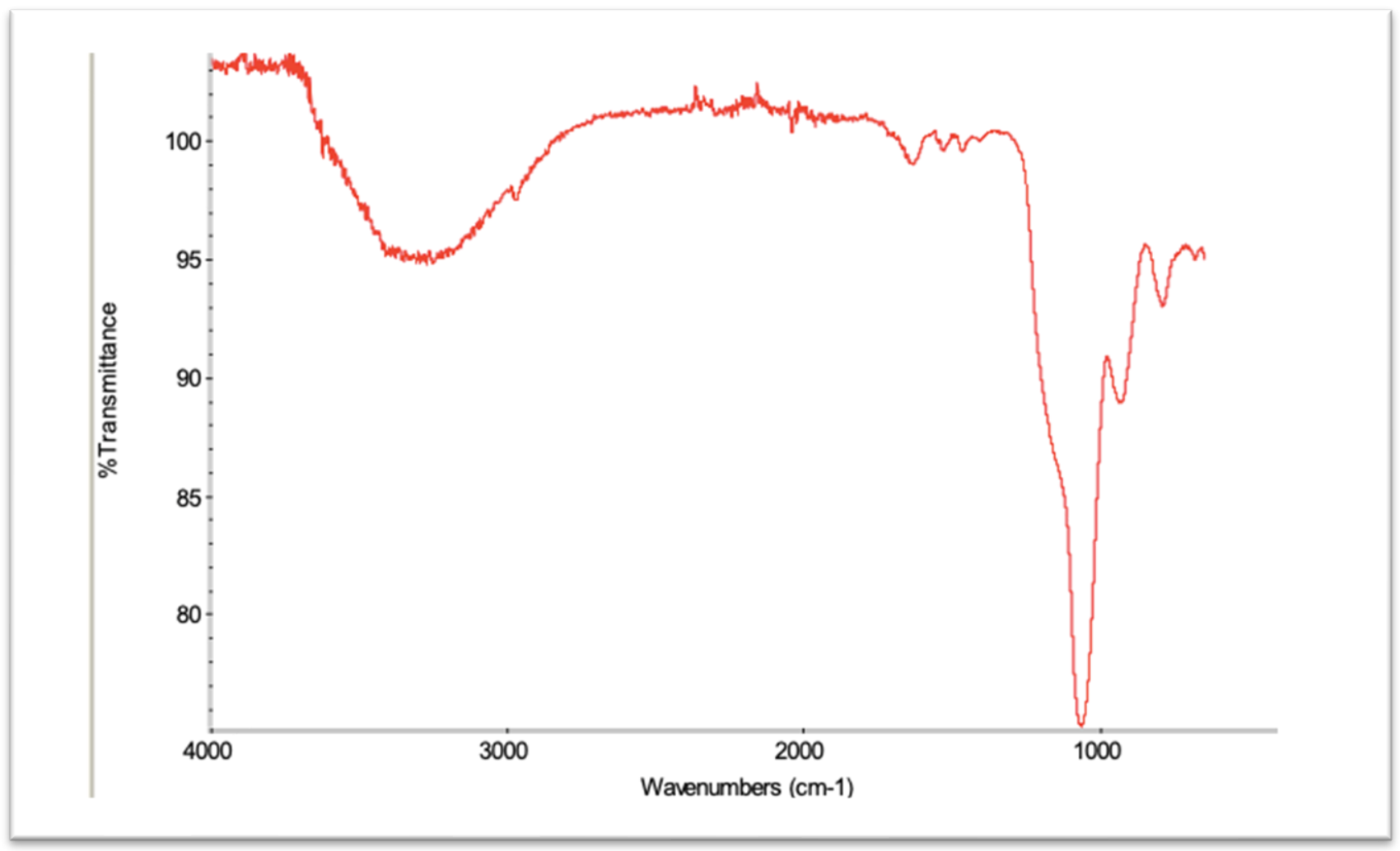

FIGURE 3. Background spectrum shows synthesis of $\mathrm{U}_{3} \mathrm{O}_{8} / \mathrm{SiO}_{2}$ nanocomposites, without the presence of catalysis. The wave located around $3259.04 \mathrm{~cm}^{-1}$ confirms $O-H$ bonds. The sharp peak around $1051.47 \mathrm{~cm}^{-1}$ indicates $\mathrm{Si}$-OR bonds. 
Once $\mathrm{U}_{3} \mathrm{O}_{8} / \mathrm{SiO}_{2}$ was constructed using the traditional sol-gel methodology, two acids were added to improve interconnectivity. Due to more background noise appearing in the 4000-3000 $\mathrm{cm}^{-1}$ region, one can confer the thermal treatment, was not as successful. The desired goal is for a clean spectrum showing a clear sharp peak around the $1000 \mathrm{~cm}^{-1}$ region with no additional functional group once proper heating treatment is in effect. Below, Figures 4 and 5 are picking up more noise in the area, showing the thermal treatment was successful but provided little to no changes within the process.

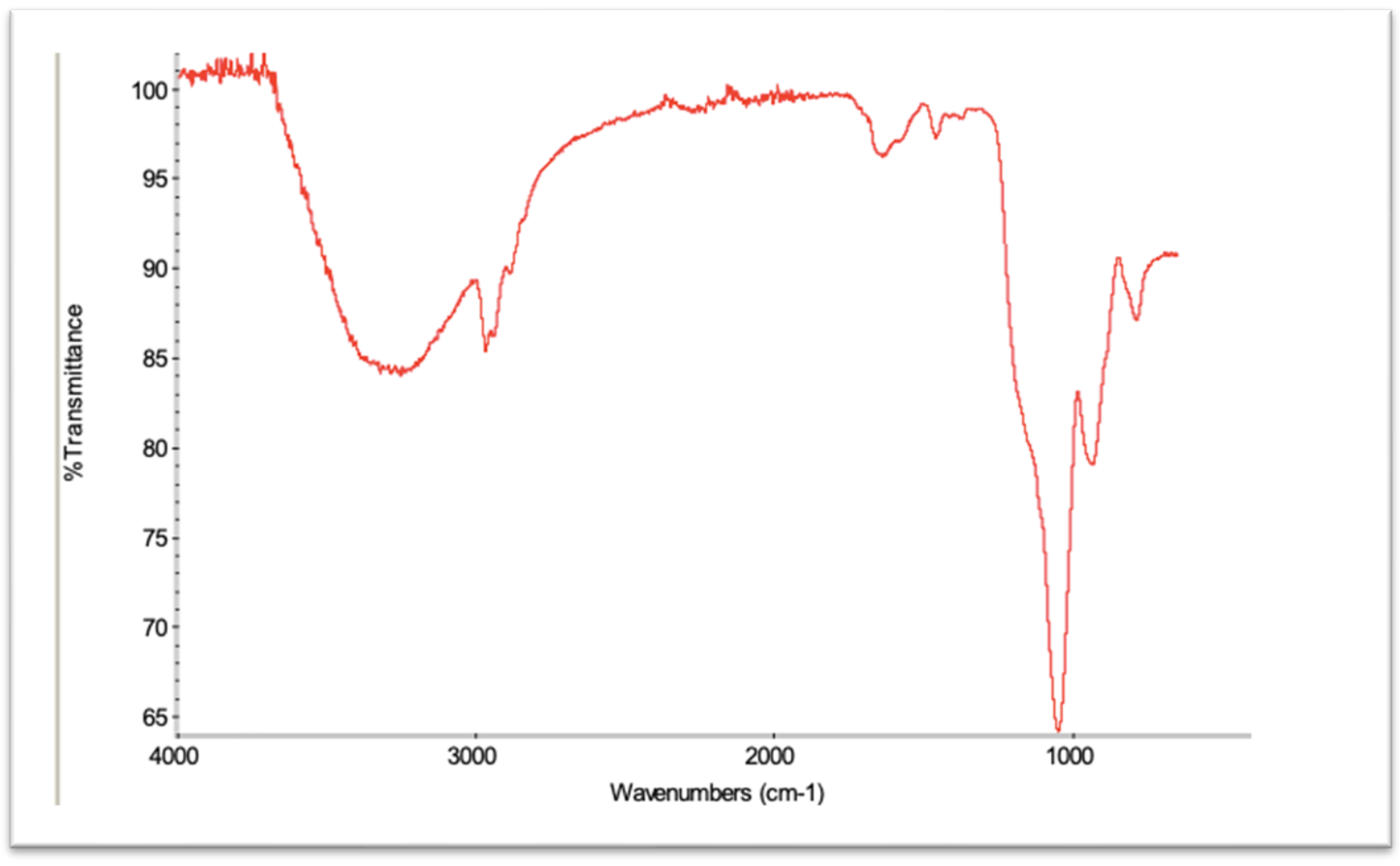

FIGURE 4. Background spectrum shows synthesis of $\mathrm{U}_{3} \mathrm{O}_{8} / \mathrm{SiO}_{2}$ nanocomposites, with the presence of catalysis, hydrochloric acid. The wave located around $3253.35 \mathrm{~cm}^{-1}$ confirms $O-H$ bonds. The sharp peak around $1050.78 \mathrm{~cm}^{-1}$ indicates $\mathrm{Si}-\mathrm{OR}$ bonds. 


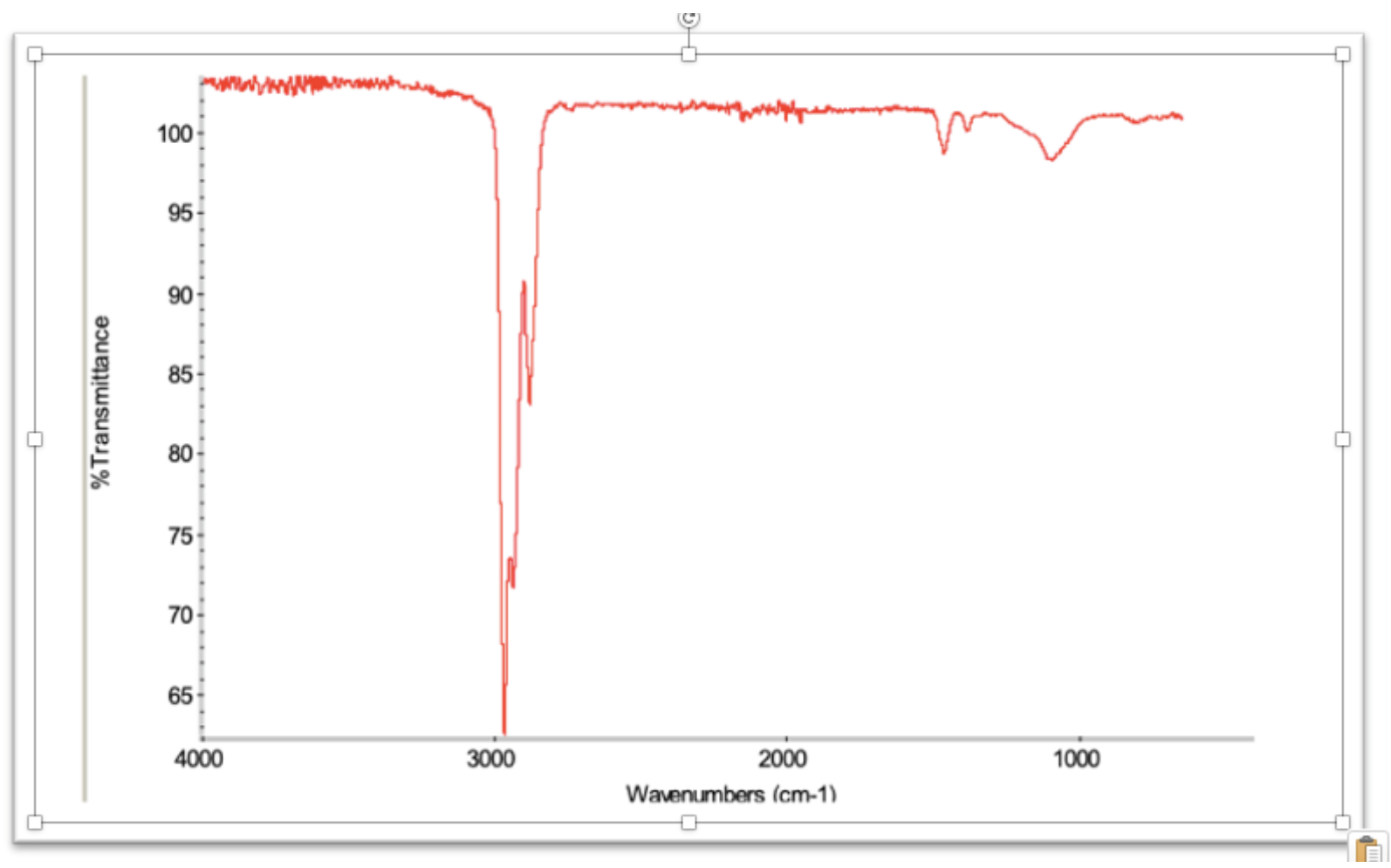

FIGURE 5. Background spectrum shows synthesis of $\mathrm{U}_{3} \mathrm{O}_{8} / \mathrm{SiO}_{2}$ nanocomposites, with the presence of catalysis, acetic acid. The wavenumber from $3555.81 \mathrm{~cm}^{-1}$ to $2880.46 \mathrm{~cm}^{-1}$ shows overtone $O-H$ stretching region. The sharp peak around $1061.42 \mathrm{~cm}^{-1}$ indicates $\mathrm{Si}-\mathrm{OR}$ bonds.

\section{Samples below will indicate formation of Si-OR bonds, with catalysis with time manipulation}

In Figures 6-7C, the experiment was conducted to compare and contrast Si-OR bonds, with/without the presence of a catalysis. The theory behind the time manipulation on the sol-gel process, states, if the acid acids can form a strong interconnected network, with an increase rate, then, the heating treatment performed on should take less time, since the bonds are stronger, performing a heating treatment should take less than four hours and form the sol-gel bonds. Based on the graphs below, one can confirm, the four hours of heating, is an essential step and must be perform for the strong Si-OR bonds. 


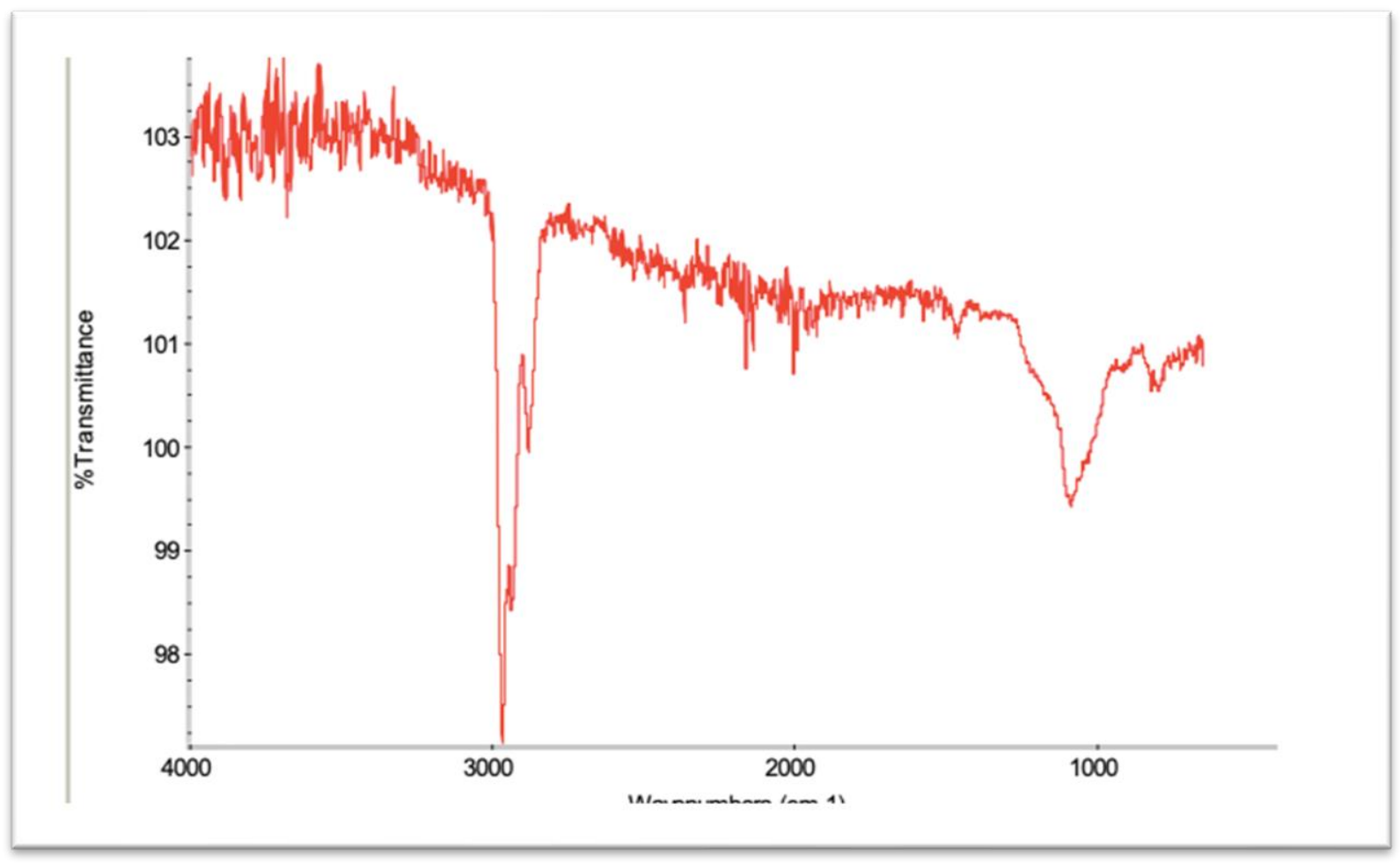

FIGURE 6A. Background spectrum shows synthesis of $\mathrm{U}_{3} \mathrm{O}_{8} / \mathrm{SiO}_{2}$ nanocomposites, with the presence of catalysis, hydrochloric acid with standard full time run in the tube furnace. The $2965.27 \mathrm{~cm}^{-1}$ indicated $O-H$ stretching. The sharp peak short peak, $1087.58 \mathrm{~cm}^{-1}$ indicates weak $\mathrm{Si}-\mathrm{OR}$ bonds. 


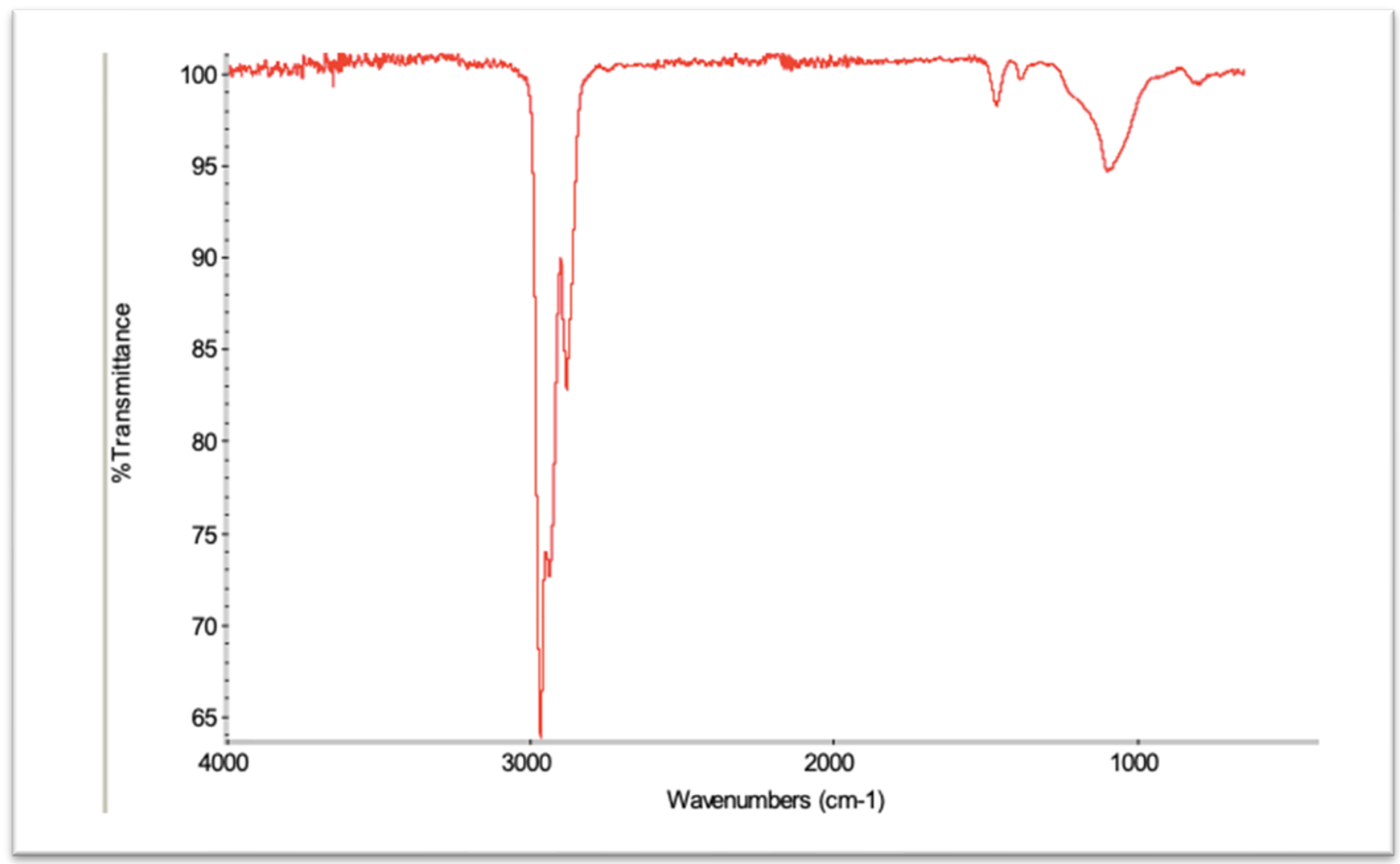

FIGURE 6B. Background spectrum shows synthesis of $\mathrm{U}_{3} \mathrm{O}_{8} / \mathrm{SiO}_{2}$ nanocomposites, with the presence of catalysis, hydrochloric acid with 1 hour run in the tube furnace. The $2965.89 \mathrm{~cm}^{-1}$ indicated $O-H$ stretching. The sharp peak short peak, $1099.78 \mathrm{~cm}^{-1}$ indicates weak Si-OR bonds. 


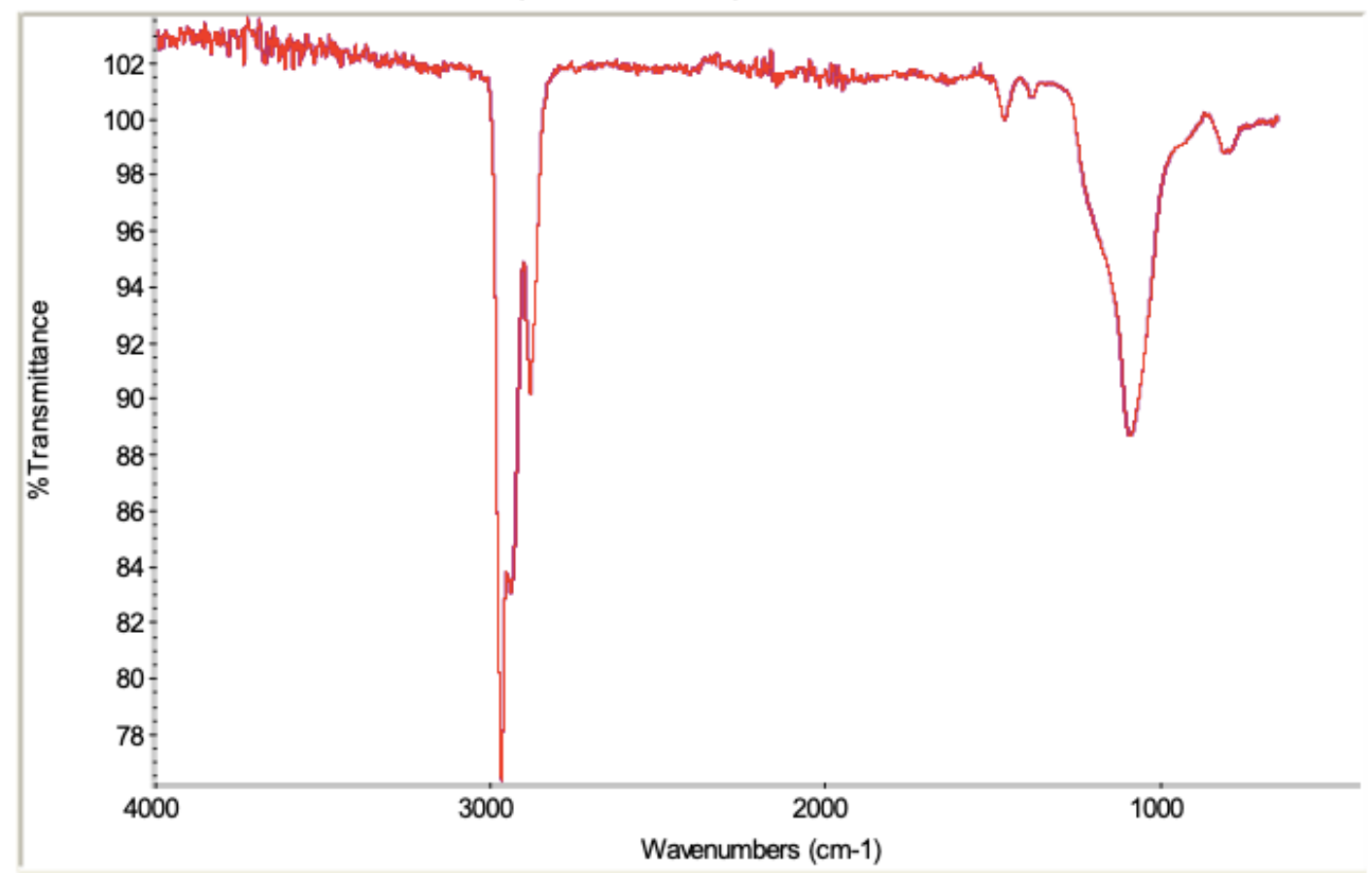

Figure 6C. Background spectrum shows synthesis of $\mathrm{U}_{3} \mathrm{O}_{8} / \mathrm{SiO}_{2}$ nanocomposites, with the presence of catalysis, hydrochloric acid with $2 \mathrm{~h}$ run in the tube furnace. The $2966.22 \mathrm{~cm}^{-1}$ indicated $O-H$ stretching. The sharp peak short peak, $1092.40 \mathrm{~cm}^{-1}$ indicates weak $\mathrm{Si}-\mathrm{OR}$ bonds. 


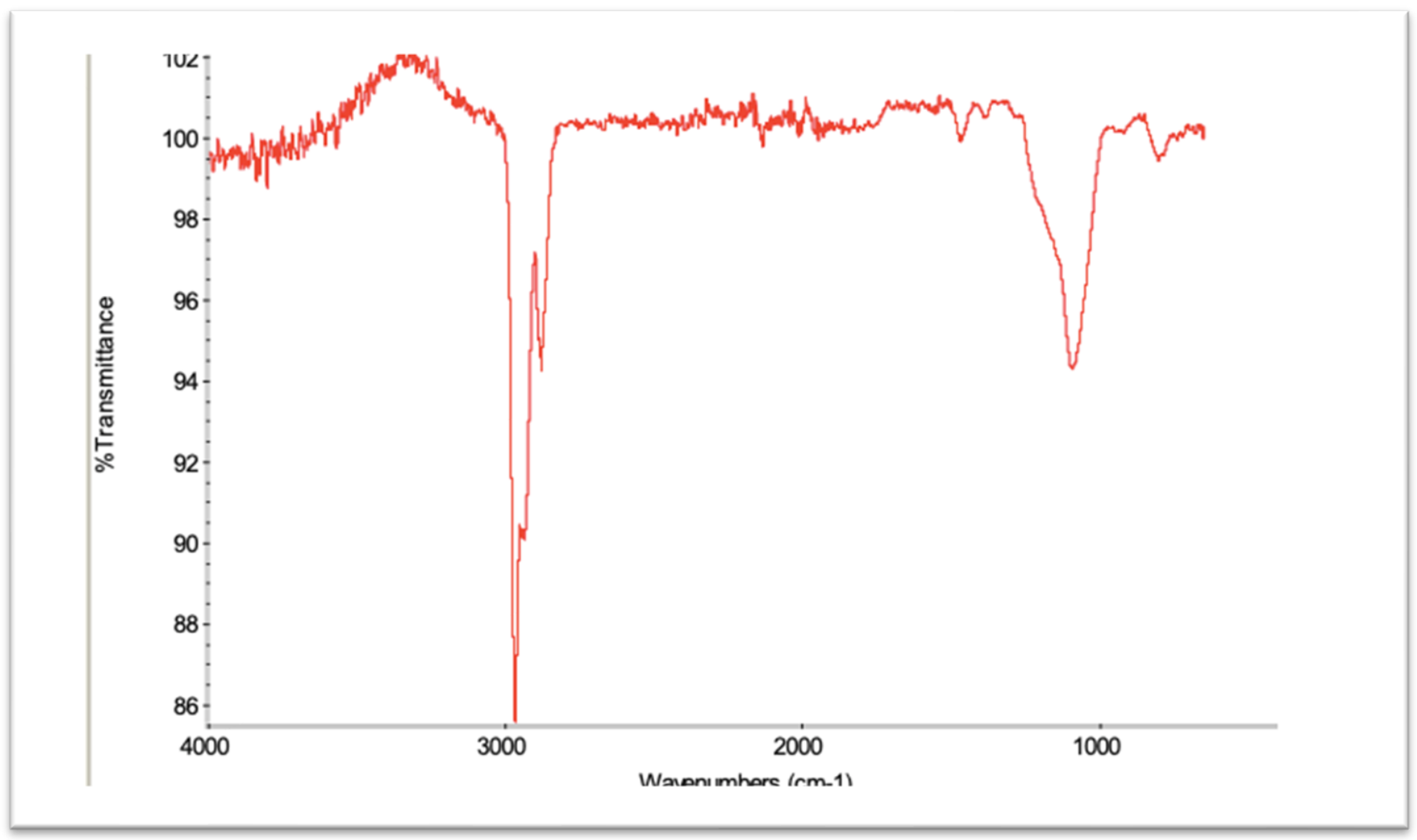

Figure 7A. Background spectrum shows synthesis of $\mathrm{U}_{3} \mathrm{O}_{8} / \mathrm{SiO}_{2}$ nanocomposites, with the presence of catalysis, acetic acid standard run time in the tube furnace. Wavenumber from 3943.91 $\mathrm{cm}^{-1}$ to $3837.44 \mathrm{~cm}^{-1}$ indicate overtone $O-H$ stretching. The sharp peak, $2967.28 \mathrm{~cm}^{-1}$, indicates $s p^{3}-\mathrm{CH}$ bonds. The short peak, $1093.58 \mathrm{~cm}^{-1}$ indicates weak $\mathrm{Si}-\mathrm{OR}$ bonds. 


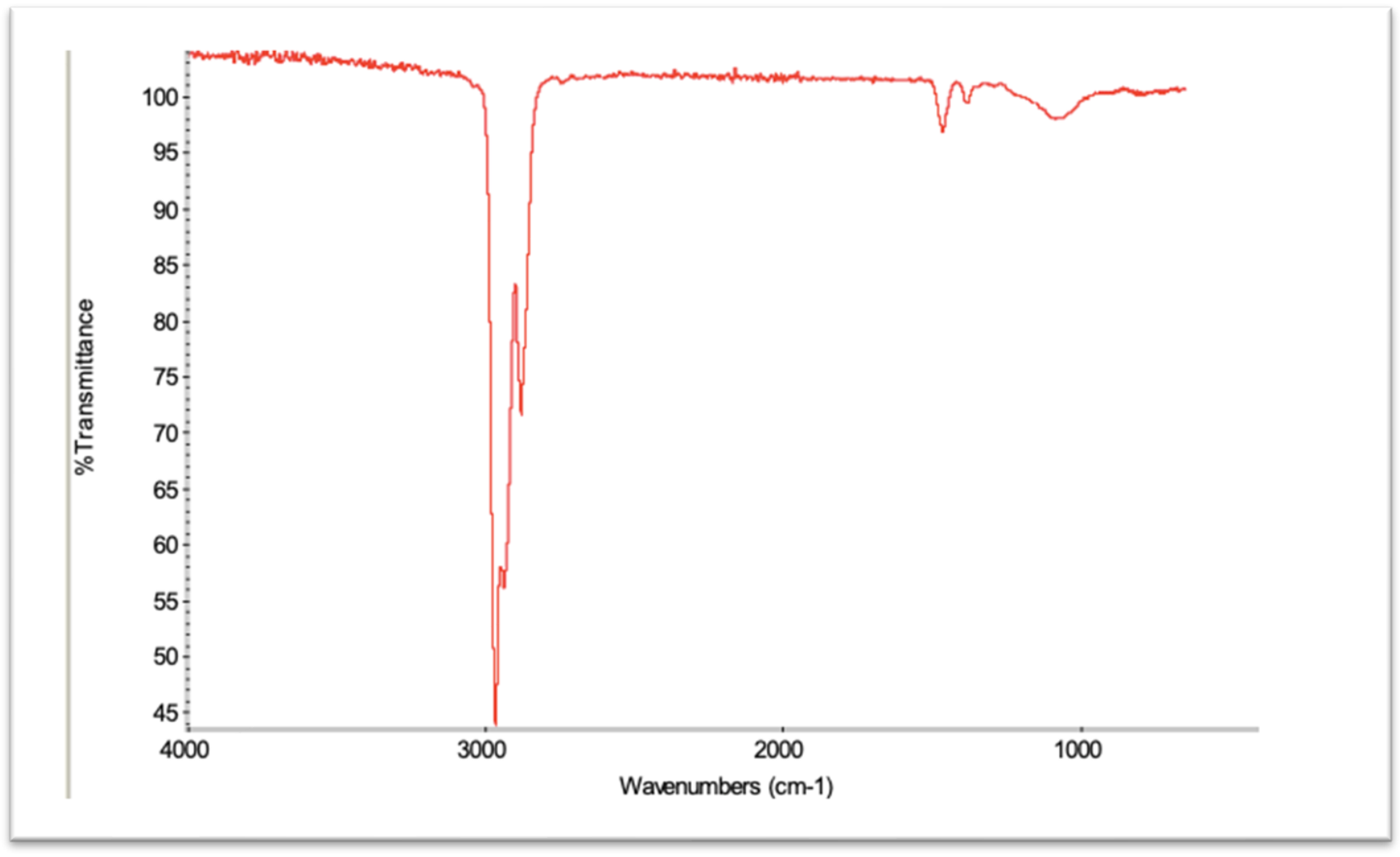

Figure 7B. Background spectrum shows synthesis of $\mathrm{U}_{3} \mathrm{O}_{8} / \mathrm{SiO}_{2}$ nanocomposites, with the presence of catalysis, acetic acid run time $1 \mathrm{~h}$ in the tube furnace. The sharp peak, 2966.10, indicates $s p^{3}-\mathrm{CH}$ bonds. The short peak, $1086.74 \mathrm{~cm}^{-1}$ indicates weak $\mathrm{Si}$-OR bonds. 


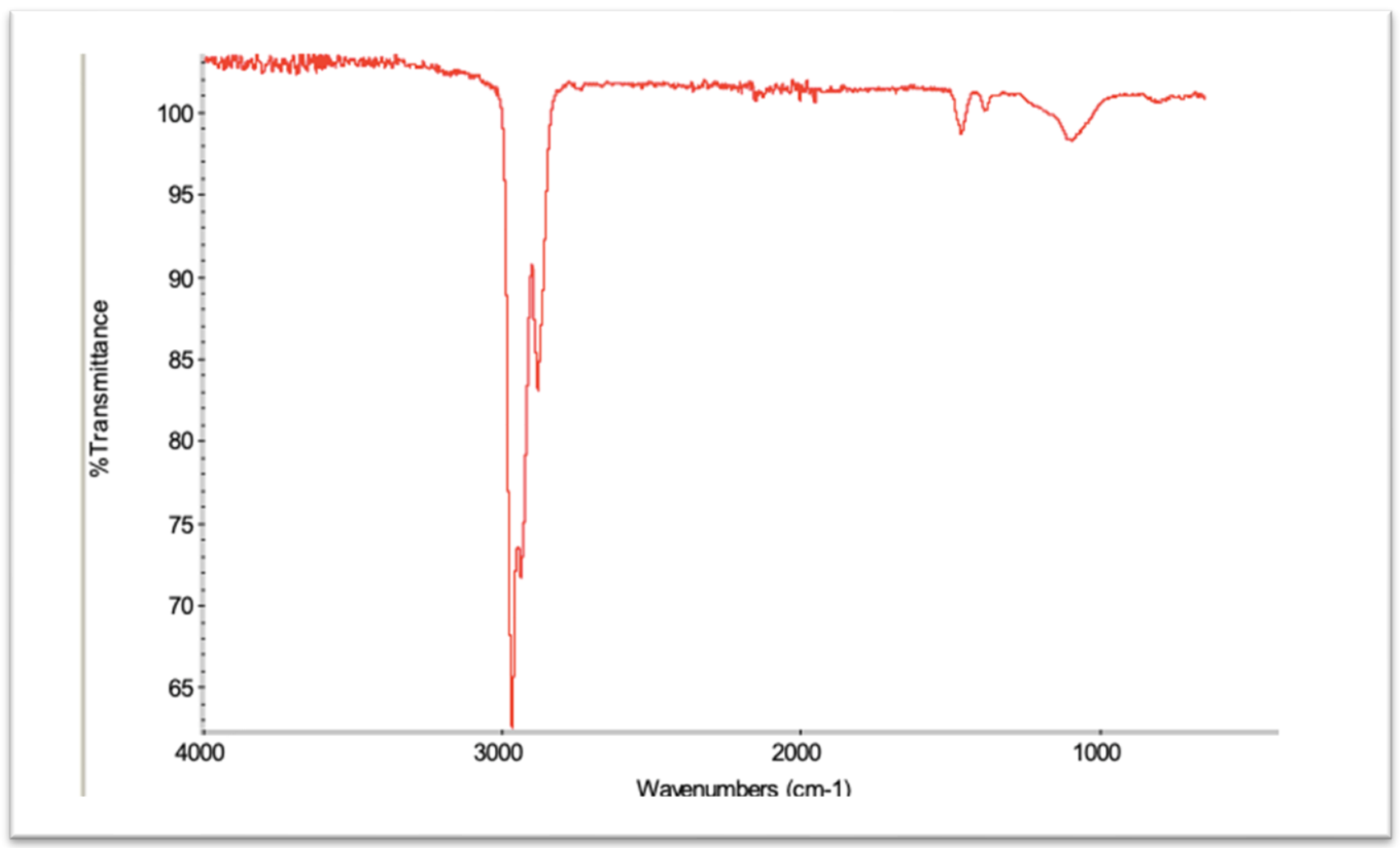

Figure 7C. Background spectrum shows synthesis of $\mathrm{U}_{3} \mathrm{O}_{8} / \mathrm{SiO}_{2}$ nanocomposites, with the presence of catalysis, acetic acid run time $2 \mathrm{~h}$ in the Tube furnace. The sharp peak, $2966.29 \mathrm{~cm}^{-1}$, indicates $s p^{3}-\mathrm{CH}$ bonds. The short peak, $1094.83 \mathrm{~cm}^{-1}$ indicates weak $\mathrm{Si}$-OR bonds.

\section{CONCLUSION}

Although one can create uranium oxide using different methodology, this paper confirms sol gel synthesis can produce $\mathrm{U}_{3} \mathrm{O}_{8} / \mathrm{SiO}_{2}$ nanocomposites. Based on the above data, one can conclude using standard conditions with the absence of hydrochloric acid and acetic acid as catalysis present can produce homogeneous nanocomposites. One can use this cheap and costeffective synthesis method and add to further application ideas on soil, water and or bacteria for further studies. 


\section{REFERENCES}

1. Poole, Charles Jr., Owens, Frank J. Introduction to nanotechnology. New Jersey: John Wiley \& Sons, Inc.; 2003.

2. M.B. Andrews, C.L. Cahill, Uranyl bearing hybrid materials: synthesis, speciation, and solid-state structures, Chem. Rev. 113 (2013) 1121-1136.

3. K.-X. Wang, J. S. Chen, Extended Structures and physicochemical properties of uranylorganic compounds, Acc. Chem. Res. 44 (2011) 531-540

4. H.D. Burrows, T.J. kemp, The photochemistry of the uranyl ion, Chem. Soc. Rev. 3 (1974) 139.

5. Z. Liao, G-D. Li, M.H. Bi, J.-S., Chen, Preparation, structures, and photocatalytic properties of three new uranyl-organic assembly compounds, Inorg. Chem. 47 (2008). 4844-4853.

6. G.E. Sigmon, P.C. Burns, Rapid self-assembly of uranyl polyhedral into crown clusters, J. Am. Chem. Soc. 133 (2011) 9137-9139.

7. J. Qiu, J. Ling, A. Sui, J.E. Szymanowsi A. Simonetti, P.C. Burns, Time-resolved, selfassembly of a fullerene-topology core-shell cluster containing 68 uranyl polyhedral, J. Am. Chem. Soc. 134 (2012) 1810-1816.

8. J. Qui, P.C. Burns, Clusters of actinides with oxide, peroxide, or hydroxide bridges, Chem. Rev. 113 (2013) 1097-1120.

9. X.L. Zhang, K.Q. Hu, L. Mei, Y.B. Zhao, Y.T. Wang, Z.F. Chai, W. Q. Shi, Semirigid tripodal ligand based uranyl coordination polymer isomers featuring $2 \mathrm{D}$ honey-comb nets, Inorg. Chem. 57(2018) 4492-4501.

10. Z. Yue, J. Lin, M. A. silver, L. Han, X. Li, J. Zhou, X. Guo, H. Bao, Y.Y. Huang, J.Q. Wang, Anionic uranyl oxyfluorides as a bifunctional platform for highly selective ionexchange and photocatalytic degradation of organic dyes, Dalton Trans. 47 (2018) 14908-14916. 